\title{
Retention of Leishmania (Leishmania) mexicana in Naturally Infected Rodents from the State of Campeche, Mexico
}

\section{Nicole R Van Wynsberghe ${ }^{+}$, Silvia B Canto-Lara, Alma G Damián-Centeno, Mateo F Itzá-Ortiz, Fernando J Andrade-Narváez}

\author{
Laboratorio de Inmunología, Centro de Investigaciones Regionales "Dr Hideyo Noguchi”, \\ Universidad Autónoma de Yucatán, Apartado Postal 2-1277, 97240, Mérida, Yucatán, México
}

In the State of Campeche, Mexico, zoonotic cutaneous leishmaniasis is mainly due to Leishmania (L.) mexicana. The parasite population is maintained in a mammalian species, a reservoir in which the ideal course of infection should be long and relatively nonpathogenic. The objective of the present study was to document the retention of $\mathrm{L}$. (L.) mexicana in 29 naturally infected rodents. These cricetids lived in captivity for up to two years and were tested monthly for the presence of the parasite, by cultures of needle aspirates from the base of the tail. Peromyscus yucatanicus and Ototylomys phyllotis were incriminated as the primary reservoir hosts. The finding that the multiplication of parasites in $\mathrm{P}$. yucatanicus might be triggered by temperature, suggests that this animal would be a good choice for further research on $\mathrm{L}$. (L.) mexicana.

Key words: Leishmania (L.) mexicana - wild rodents - reservoir - retention - Mexico

Leishmaniasis is a complex of human diseases with complicated transmission cycles and the parasite, Leishmania Ross, 1903 is distributed throughout most of the tropics and sub-tropics. The leishmaniases are endemic in at least 22 countries of Latin America (WHO 1990). Zoonotic cutaneous leishmaniasis (ZCL) due to $L$. (L.) mexicana has been identified both in Belize and Mexico (Lainson \& Strangways-Dixon 1964, Chance et al. 1974, Gardener et al. 1974, Moreno et al. 1986, Barker et al. 1986, Grimaldi et al. 1987, Cupolillo et al. 1994, Chablé-Santos et al. 1995, Canto-Lara et al. 1999). In the latter, leishmaniases have been recorded in 17 states, where localized cutaneous leishmaniasis (LCL) is the most common clinical form (Seidelin 1912, Velasco-Castrejón et al. 1997).

In the State of Campeche, LCL is a wild zoonosis (Andrade-Narváez et al. 1990, Chablé-Santos et al. 1995, Rebollar-Téllez et al. 1996). Four rodent species Sigmodon hispidus Say and Ord, 1825; Oryzomys melanotis Hooper, 1953; Ototylomys phyllotis Merriam, 1901; and Peromyscus yucatanicus JA Allen and Chapman, 1897 (Rodentia: Cricetidae) have been reported naturally in-

This investigation received support from the UNDP/ World Bank/WHO Special Programme for Tropical Diseases Research: RCS/TDR/WHO ID 900248.

${ }^{+}$Corresponding author. Fax: (99) 23-61-20. E-mail: nvan@tunku.uady.mx

Received 28 May 1999

Accepted 24 May 2000 fected (Chablé-Santos et al. 1995). Most of the infected animals presented dermal lesions on the tail but in some specimens the infection was asymptomatic. Leishmania (L.) mexicana Biagi, 1953 emend. Garham, 1962 is the main agent of ZCL in the State of Campeche (Pérez-Mutul et al. 1994, Canto-Lara et al. 1998, 1999) and was characterized by using an indirect immunofluorescence assay with monoclonal antibodies in two S. hispidus, eight Or. melanotis, six Ot. phyllotis, and five $P$. yucatanicus (Canto-Lara et al. 1999).

Leishmania needs a mammalian species, a reservoir, to maintain the parasite population (WHO 1984,1990 , Bray 1987). Ideally, the course of infection should be long and relatively nonpathogenic, and the parasites should be available in the skin or the blood in sufficient numbers for the sand fly vector (WHO 1984, 1990, Bray 1987). To document this requirement in the field is nearly impossible due to the small sample-size of infected individuals and the low probability of recapture.

Thus, the objective of the present study was to document the retention of $L$. (L.) mexicana in 29 naturally infected rodents from the State of Campeche, kept in captivity in Mérida, Yucatán, Mexico. These captive cricetids lived for up to two years during which the course of infection was following up by parasitological methods.

\section{MATERIALS AND METHODS}

Animal care - Twenty-nine naturally infected rodents (2 S. hispidus, 12 Or. melanotis, 9 Ot. phyllotis, and 6 P. yucatanicus) were captured in La Libertad, State of Campeche, Mexico, between 
November 1993 and March 1994 (Chablé-Santos et al. 1995). The animals were housed individually and fed rabbit chow (Provi, Mérida, Yucatán). Corn, sunflower seed, vegetable, or fruit were added at weekly intervals during the period of acclimation to captivity (one month). Air-conditioning was turned on during daytime and a ceiling ventilator during the night. The environmental conditions of the animal-care facilities were not measured and variations might have occurred. In general, the temperatures inside were cooler during the dry season (April to June).

Retention of parasite and evolution of lesion The 29 infected rodents were observed for up to two years (November 1993 to October 1995). Each month, changes in the appearance of the lesion were recorded and needle aspirates made from the skin lesions were cultured in modified Senekjie's medium (Vouldoukis et al. 1987, Weigle et al. 1987). The cultures were kept at $22^{\circ} \mathrm{C}$ and checked weekly under a Zeiss light microscope (Standard 25) with a 100/1.25 oil magnifier using culture material stained with Giemsa. An animal was considered positive when at least one promastigote was observed microscopically and negative if no parasites were found within the month. When five or more rodents of the same species were available, nonparametric binomial tests were performed, using the number of positive and negative results of each animal, to find if the distribution of positive cultures was significantly different from the negative ones within each species (Dixon et al. 1990). The survival difference between the heavily and lightly infected animals was estimated using the KaplanMeier method with four non-parametric linear rank tests (Mantel-Cox, Tarone-Ware, Wilcoxon/ Breslow, Wilcoxon/Peto-Prentice - Dixon et al. 1990). Given the small sample of animals, the results should be interpreted with care.

Systemic dissemination - Five euthanized animals and the ten individuals remaining at the end of the study, were killed with chloroform, weighed, measured, and checked for any external and/or internal signs of infection. In healthy small rodents, popliteal lymph nodes are never visible but they sometimes become apparent when infected. In the latter, impressions of cut lymph nodes were made on microscopic slides, stained with Giemsa, and checked for amastigotes by light microscopy. Smears were also taken from liver and spleen. In ten animals, smears were taken from kidney and heart. Nineteen voucher specimens (skin and skeleton) were prepared (Nagorsen \& Peterson 1980) for the museum of the School of Biology of the Universidad Autónoma de Yucatán, Mérida, Mexico and the Royal Ontario Museum, Toronto, Canada.

\section{RESULTS}

Animal care - The 29 naturally infected rodents were acclimatised to captivity and lived for up to two years (Table I). No statistical difference was found in the survival rates of heavily and lightly infected animals.

Retention of the parasite - Aspirates were cultured monthly but some of the cultures were contaminated and did not yield any result. No aspirates could be taken during the months of January, April, and August 1994.

Parasites were consistently demonstrated during 15 months in one S. hispidus (S-A2) (Table I). On the other hand, the second Sigmodon (S-N5) showed parasites irregularly during 21 months. No statistical test could be performed since the number of specimens of hispid cotton-rat was too low.

Oryzomys melanotis consistently retained parasites at the site of the infection (Table I). Individual black-eared rice-rats had a significantly higher number of positive cultures than negative $\left(\mathrm{Z}_{\text {observed }}=-3.614, \mathrm{Z}_{0.01}=-2.58\right)$. Both healthy and infected colonies of Oryzomys had high mortality rates (100\% and $80 \%$ respectively).

Four Ot. phyllotis (Ot-C9, Ot-K5, Ot-6a, and Ot-C4) were used for the colony and were not sampled during reproduction. The nine big-eared climbing rats retained parasites very irregularly (Table I). Three of them (Ot-K5, Ot-C4, and OtS12) were positive at capture and negative afterward. However, three Ototylomys (Ot-B4, Ot-S9, and Ot-Q9) retained parasites consistently for at least 18 months. The distribution of positive cultures was not significantly different from the negative ones $\left(Z_{\text {observed }}=-0.9267, Z_{0.05}=-1.96\right)$.

The retention of parasites was very irregular in the five P. yucatanicus studied (Table I). Monthly aspirates gave significantly more negative results than positive $\left(Z_{\text {observed }}=-3.5717, Z_{0.01}=-2.58\right)$. However, the parasite was found in all infected Yucatán deer-mice in the months of June 1994 and May 1995.

Evolution of the lesion - The clinical signs observed in the two infected S. hispidus differed widely. In November 1993, S-A2 presented an ulcer at the base of the tail, similar to the craterlike lesion frequently observed in humans. The ulcer closed during January 1994, but the site of infection remained very swollen and discolored. Metastases were slowly evident in other parts of the body, first in the fleshy area around the anus, then in November 1994, in the depilating rump and swelling ears. In February 1995, this cotton-rat was very weak and was euthanized. On the other hand, the second Sigmodon (S-N5) remained very healthy-looking and presented only one white spot of $3 \mathrm{~mm}$ in diameter on the proximal third of tail. 
Infected Or. melanotis always presented some visible signs of leishmaniasis: red, hairless spots and/ or swelling on the proximal third of the tail. One of these black-eared rice-rats (Or-C8) developed an ulcer which healed a month later. Two rice-rats (Or$\mathrm{O} 2$ and Or-D9) presented depilation of the rump and died soon after. At the end of the two years, the two remaining Oryzomys (Or-F9 and Or-C8) presented discolored areas along the whole tail.
The lesions of both Ot. phyllotis and P. yucatanicus remained mostly inconspicuous as when first captured (Chablé-Santos et al. 1995). One Yucatán deer-mouse (P-B2) died during manipulation and presented a depilated area on the rump.

Systemic dissemination - Only the euthanized animals could be tested for internal dissemination of the parasites. The popliteal lymph nodes of $S$.

\section{TABLE I}

Monthly distribution of Leishmania (Leishmania) mexicana $(\mathrm{LLm})$ in cultures of tail aspirate of 29 naturally infected rodents from La Libertad, Campeche, Mexico

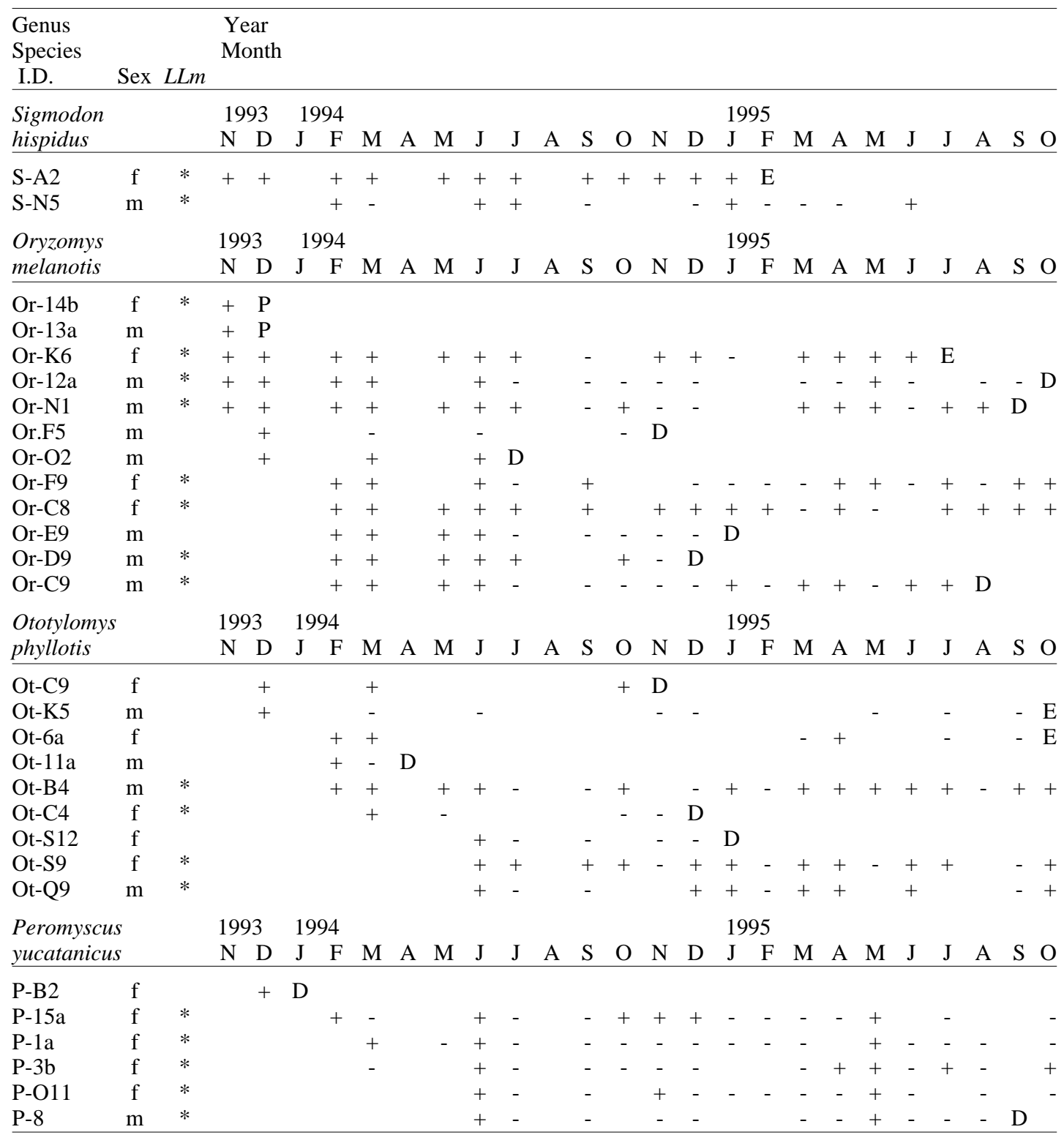

I.D.: identification; m: male; f: female; *: characterized by McAbs (Canto-Lara et al. 1999); culture of aspirate: positive +; negative -; D: animal died; E: animal euthanized. 
hispidus (S-A2) were black and swollen. Impression smears of liver, spleen, and lymph nodes were found positive for the parasite. In October 1995, when the second cotton-rat (S-N5) was euthanized no popliteal lymph node was visible but amastigotes was found in liver (Table II).

Two Or. melanotis (Or-14b and Or-13a), checked at the start of the study, did not present any parasite in the cultures of macerated liver and spleen. One rice-rat (Or-K6) euthanized because of respiratory distress and two others (Or-C8 and Or-F9) checked at the end of the research had amastigotes in liver and spleen (Table II). One of those rats (Or-C8) had enlarged liver with granuloma, enlarged spleen, edema in thorax, abdomen and subcutanea.

Amastigotes were found in the liver of only one of the six Ot. phyllotis checked (Table II). This climbing rat (Ot-Q9) also presented abdominal and subcutaneous edema.

The four $P$. yucatanicus tested presented amastigotes in every organ (Table II). However, previous to collecting, those Yucatán deer-mice were part of a two-years capture-mark-recapture research. Three of the deer-mice (P-15a, P-1a, and $\mathrm{P}-3 \mathrm{~b}$ ) were more than three years old.

\section{DISCUSSION}

To incriminate a reservoir host, it is neccessary to demonstrate that the parasite population needs that particular mammal for the maintenance of the disease in a given focus. This demands extensive

\section{TABLE II}

Distribution of Leishmania (Leishmania) mexicana in smears of organs of naturally infected rodents from $\mathrm{La}$ Libertad, Campeche, Mexico

\begin{tabular}{llcccc}
\hline Species & I.D. & Liver & Spleen & Kidney & Heart \\
\hline Sigmodon & S-A2 & + & + & & \\
hispidus & S-N5 & + & - & & \\
Oryzomys & Or-K6 & + & + & & \\
melanotis & Or-F9 & + & + & & \\
& Or-C8 & + & - & & \\
Ototylomys & Ot-K5 & - & - & - & - \\
phyllotis & Ot-6a & - & - & - & - \\
& Ot-B4 & - & - & - & - \\
& Ot-C4 & - & - & - & - \\
& Ot-S9 & - & - & - & - \\
& Ot-Q9 & + & - & - & - \\
Peromyscus & P-15a & + & + & + & + \\
yucatanicus & P-1a & + & + & + & + \\
& P-3b & + & + & + & + \\
& P-O11 & + & + & + & + \\
\hline
\end{tabular}

I.D.: identification; smear: positive + ; negative - ecological studies. In general, full objective incrimination is not possible and any conclusion depends on the accumulation of evidence on five criteria (WHO 1984, 1990). Two of them have been demonstrated previously (Chablé-Santos et al. 1995, Canto-Lara et al. 1999). The present study presented evidence for the following criteria:

First, the parasites, in a good mammalian reservoir, should be available in the skin or blood in sufficient number to be taken up by the sand fly vector (WHO 1984, Bray 1987). The quantity of parasites needed to infect a sand fly is not known. The proliferation of Leishmania in the studied rodents was not quantified. A culture became positive when parasites were aspirated in sufficient quantity to seed the medium. Since the site of infection was very restricted and sometimes asymptomatic, the aspirate was not always successful. Similarly, Herrer et al. (1971) stated that aspirates or smears made some millimeters away, from known leishmanial lesions of Or. capito Handley, 1966 found naturally infected, gave negative results. These problems in obtaining the parasite in culture, might also be experienced by the phlebotomine vector.

Most of the year, P. yucatanicus showed no presence of parasite. However, since the parasites were encountered in June 1994 and May 1995 in all five mice, Leishmania must have been present during the whole research. The presence of cryptic parasites have been indirectly proven in humans (Aragort de Rossell et al. 1992, Alvar et al. 1997) and because of the small quantity, they would not harm the host. The fact that all the Yucatán deermice showed the parasites at the same time suggests the existence of a trigger for parasites multiplication. All infected rodents were captured between November 1993 and February 1994, the coolest months of the year in the study site. Thus, the trigger for parasite multiplication in the present deer-mice might be the temperature. In the animalcare facility, the air conditioners were functioning more during the hottest months, May to July. Thus, the peaks of parasite proliferation in captivity did not correspond to the one in the field, but both seemed to be related to temperature. Kerr et al. (1995) suggested that the absence of detectable infections they encounted in summer may be explained by the inhibition of growth of $L$. (L.) mexicana at or above $37^{\circ} \mathrm{C}$.

Second, the course of infection should be long and the reservoir host long-lived to provide a significant source of infection for the sand flies (WHO 1984). In the field, S. hispidus does not live for more than six months (Odum 1955, Cameron \& McClure 1988) while Ot. phyllotis and $P$. yucatanicus live for more than two years (Van Wynsberghe, unpublished data). The high rate of 
mortality in captive Or. melanotis demonstrated the sensivity of the black-eared rice-rats to environmental conditions and its probable short life-span.

One S. hispidus consistently kept the parasites during 15 months while the second kept the parasites irregularly during 21 months. Similarly, three Ot. phyllotis did not retain the parasite, while three others retained the parasite consistently during the two years (Table I). Thus, the sampled area in Campeche might contain mixed populations within each of those two species, resistant and susceptible to $L$. (L.) mexicana.

All the Oryzomys retained the leishmanial parasite consistently $(\mathrm{P}<0.05)$. Because of its good retention of the parasite, the black-eared rice-rat could be an effective reservoir of $L$. (L.) mexicana. However, the low relative abundance of the blackeared rice-rats limited its importance as an effective reservoir host (Chablé-Santos et al. 1995). Herrer et al. (1971) found a similar population decrease after trapping Or. capito.

Third, in a reservoir species, the infection should be relatively nonpathogenic (WHO 1984). In general, the clinical signs of leishmaniasis in Ot. phyllotis were small or not existent and the infection seemed harmless. Similarly, the infection in black-eared rice-rats and Yucatán deer-mice did not seem to endanger their life in captivity. This asymptomatic infection with little or no pathology probably results from a well balanced and probably ancient hostparasite relationship (Lainson \& Shaw 1979).

The finding of systemic dissemination of $L$. (L.) mexicana in naturally infected rodents came as a surprise (Table II). Disney (1964) found visceral involvement probably due to $L$. (L.) mexicana in one Heteromys desmarestianus Desmarest, 1817 emend. Goldman, 1911 from Belize; however, the Heteromyidae are phylogenetically very different from the Cricetidae here studied. Lainson and Strangways-Dixon (1964), in a study on the reservoir hosts of $L$. (L.) mexicana among the forest rodents carried out in British Honduras, found naturally infected $O t$. phyllotis, $H$. desmarestianus, Nyctomys sumichrasti Saussure, 1860 and the infections were purely cutaneous. Similarly, Herrer et al. (1971) did not find any parasite in liver, spleen, heart blood, and bone marrow of 26 Or. capito presenting caudal lesions infected with flagellates causing in golden hamster lesions similar to those of $L$. (L.) mexicana. Lainson and Shaw (1979) stated that, in rodents, the division between cutaneous and visceral leishmaniases is not always clear. However, the occurrence of amastigotes of $L$. (L.) mexicana in organs of the cricetids studied should not be considered as visceralization of the disease, since their effect was non-pathogenic.

In this study, the presence of the parasite in organs could be related to the age of the mice and rats as a consequent depression of the immune response (Bach 1982). The age of the 29 naturally infected rodents was not known at capture, however, all presented adult characteristics such as pelage, weight, and reproductive activity (scrotal open vagina, pregnant, or lactating). The two $S$. hispidus could be considered very old since this species live up to six months in the wild (Odum 1955, Cameron \& McClure 1988). Only two Oryzomys from both the healthy $(\mathrm{N}=20)$ and the infected $(\mathrm{N}=8)$ colonies survived the two-years research. Three of the four Peromyscus with amastigotes in the organs were more than three years old as proven by a two-years ecological study, previous to collecting.

The lack of systemic dissemination in three $O t$. phyllotis (Ot-K5, Ot-6a, and Ot-B4) might be due to the fact that those climbing rats did not retain the parasite (Tables I, II). The last three Ototylomys tested for systemic dissemination were not infected except one liver with very few amastigotes. The big-eared climbing rat had very little cutaneous signs of infection and showed the parasites very irregularly, thus demonstrating their relative resistance to $L$. (L.) mexicana.

The results of the present laboratory research in combination with those of the field study (Chablé-Santos et al. 1995) confirms the role of Ot. phyllotis as a primary reservoir-host of $L$. (L.) mexicana, and indicates that $P$. yucatanicus is of similar importance in the Campeche focus of infection. The existence of cryptic parasites in $P$. yucatanicus during most of the year and the possible presence of an environmental trigger during the transmission season, makes the Yucatán deermouse in the best choice as both a primary reservoir in this area, and an animal model for further research on $L$. (L.) mexicana.

\section{ACKNOWLEDGEMENTS}

To Nubia A Rivero-Cárdenas, Blanca M Vera-Ku, and Fanny Ojeda-Farfán for their help with the aspirates; to the staff of the animal-house; to Dr José A GóngoraAldaz from the Statistical Consultancy Services of the Faculty of Mathematics of the UADY for the quantitative analysis of the data; to Nelly E Albertos-Alpuche, Hugo Ruiz-Piña, and Dr Eric Dumonteil for the editing of the manuscript.

\section{REFERENCES}

Alvar J, Cañavate C, Gutiérrez-Solar B, Jiménez M, Laguna F, López-Vélez R, Molina R, Moreno J 1997. Leishmania and human immunodeficiency virus coinfection: the first 10 years. Clin Microbiol Rev 10: 298-319.

Andrade-Narváez FJ, Simmonds-Díaz E, Rico-Aguilar S, Andrade-Narváez M, Palomo-Cetina A, CantoLara SB, García-Miss MR, Madera-Sevilla M, Albertos-Alpuche N 1990. Incidence of localized 
cutaneous leishmaniasis (chiclero's ulcer) in Mexico. Trans R Soc Trop Med Hyg 84: 219-220.

Aragort de Rossell R, de Durán R de J, Rossell O, Rodríguez AM 1992. Is leishmaniasis ever cured? Trans R Soc Trop Med Hyg 86: 251-253.

Bach JF 1982. The immune deficiency of aging. In JF Bach, Immunology, 2nd ed., John Wiley \& Sons Inc, New York, p. 901-902.

Barker DC, Butcher J, Gibson LJ, Kennedy WPK, Williams RH, Cuba Cuba CA, Marsden PD, Lainson R, Shaw JJ 1986. Sequence homology of kinetoplast DNA in Leishmania studied by filter hybridisation of endonuclease digested fragments and "in situ" hybridisation of individual organisms. In J-A Rioux, Leishmania. Taxonomie et Phylogenèse: Applications Éco-épidémilogiques, Montpellier, Colloque International CNRS/INSERM, IMEEE, p. 41-55.

Bray RS 1987. Zoonoses and leishmaniasis. In DT Hart, Leishmaniasis: the Current Status and New Strategies for Control, Plenum Press, New York, p. 57-60.

Cameron GN, McClure PA 1988. Geographic variation in life history traits of the hispid cotton-rat (Sigmodon hispidus). In MS Boyce, Evolution of Life Histories of Mammals: Histories and Patterns, Yale University Press, New Haven, p. 33-64.

Canto-Lara SB, Cárdenas-Marrufo MF, VargasGonzález A, Andrade-Narváez FJ 1998. Isoenzyme characterization of Leishmania isolated from human cases with localized cutaneous leishmaniasis from the State of Campeche, Mexico. Am J Trop Med Hyg 58: 444-447.

Canto-Lara SB, Van Wynsberghe NR, Vargas-González A, Ojeda-Farfán FF, Andrade-Narváez FJ 1999. Identification by monoclonal antibodies of Leishmania spp. isolated from humans and wild rodents in the State of Campeche, Mexico. Mem Inst Oswaldo Cruz 94: 305-309.

Chablé-Santos JB, Van Wynsberghe NR, Canto-Lara SB, Andrade-Narváez FJ 1995. Isolation of Leishmania $(L)$ mexicana from wild rodents and their possible role in the transmission of localized cutaneous leishmaniasis in the State of Campeche, Mexico. Am J Trop Med Hyg 53: 141-145.

Chance ML, Peters W, Shchory L 1974. Biochemical taxonomy of Leishmania. I: Observations on DNA. Ann Trop Med Parasitol 68: 307-316.

Cupolillo E, Grimaldi Jr G, Momen H 1994. A general classification of New World Leishmania using numerical zymotaxonomy. Am J Trop Med Hyg 50: 296-311.

Disney RHL 1964. Visceral involvement with dermal leishmaniasis in a wild-caught rodent. Trans $R$ Soc Trop Med Hyg 58: 581.

Dixon WJ, Brown MB, Engelman L, Jennrich RI 1990. BMDP Statistical Software Manual, Vol. 1, University of California Press, USA, 734 pp.

Gardener PJ, Chance ML, Peters W 1974. Biochemical taxonomy of Leishmania. II: Electrophoretic variation of malate dehydrogenase. Ann Trop Med Parasitol 68: 317-325.

Grimaldi Jr G, David JR, McMahon-Pratt D 1987. Identification and distribution of New World Leishmania species characterized by serodeme analysis us- ing monoclonal antibodies. Am J Trop Med Hyg 36: 270-287.

Herrer A, Telford Jr SR, Christensen HA 1971. Enzootic cutaneous leishmaniasis in eastern Panama. I. Investigation of the infection among forest mammals. Ann Trop Med Parasitol 65: 349-358.

Kerr SF, McHugh CP, Dronen Jr NO 1995. Leishmaniasis in Texas: prevalence and seasonal transmission of Leishmania mexicana in Neotoma micropus. Am J Trop Med Hyg 53: 73-77.

Lainson R, Shaw JJ 1979. The role of animals in the epidemiology of South American leishmaniasis. In WHR Lumsden, DA Evans (eds), Biology of the Kinetoplastida, Vol. 2, Academic Press Inc, p. 1-116.

Lainson R, Strangways-Dixon J 1964. The epidemiology of dermal leishmaniasis in British Honduras. Part II. Reservoir hosts of Leishmania mexicana among the forest rodents. Trans $R$ Soc Trop Med Hyg 58: 136-153.

Moreno G, Pratlong F, Velez ID, Restrepo M, Rioux JA 1986. Individualisation du complexe Leishmania guyanensis. A propos de l'analyse numérique de sept zymodèmes. In J-A Rioux, Leishmania. Taxonomie et phylogenèse: Applications éco-épidémilogiques, Montpellier, Colloque International CNRS/ INSERM, IMEEE, p. 165-172.

Nagorsen DW, Peterson RL 1980. Mammal Collectors' Manual: a Guide for Collecting, Documenting, and Preparing Mammal Specimens for Scientific Research, Life Sciences Miscellaneous Publications, Royal Ontario Museum, Toronto, Canada, 79 pp.

Odum EP 1955. An eleven-year history of a Sigmodon population. J Mamm 56: 368-378.

Pérez-Mutul J, Balam-Tzeek L, Canto-Lara SB 1994. Identificación de protozoarios del género Leishmania con sondas biotinadas de kDNA en la Península de Yucatán, México. Rev Biomedica (Mex) 5: 60-69.

Rebollar-Téllez EA, Ramírez-Fraire A, AndradeNarváez FJ 1996. A two-years study on vectors of cutaneous leishmaniasis. Evidence for sylvatic transmission cycle in the State of Campeche, Mexico. Mem Inst Oswaldo Cruz 91: 555-560.

Seidelin H 1912. Leishmaniasis and babesiasis in Yucatán. Ann Trop Med Parasitol 6: 295-298.

Velasco-Castrejón O, Walton BC, Rivas-Sánchez B, García MF, Lázaro GJ, Hobart O, Roldan S, FlorianiVerdugo J, Munguía-Saldana A, Berzaluce R 1997. Treatment of cutaneous leishmaniasis with localized current field (radio frequency) in Tabasco, Mexico. Am J Trop Med Hyg 57: 309-312.

Vouldoukis I, Monjour L, Frommel D, Rosenheim M, Datry A, Colomb-Vallet A, Gentilini M 1987. Prélèvement par aspiration à l'aiguille dans le diagnostic de la leishmaniose cutanée. Presse Médicale 16: 76-77.

Weigle KA, de Dávalos M, Heredia P, Molineres H, Saravia NG, Alessandro A 1987. Diagnosis of cutaneous and mucocutaneous leishmaniasis in Colombia: a comparision of seven methods. Am J Trop Med Hyg 36: 489-496.

WHO-World Health Organization 1984. The Leishmaniases, WHO Technical Report Series 701.

WHO-World Health Organization 1990. Control of the Leishmaniases, WHO Technical Report Series 793. 